\title{
STUDY ON ZOONOSES AND PREVENTIVE AND CONTROL MEASURES IN THE ARAB WORLD
}

\author{
Dr. Jeblawi, $R$. \\ Department of Animal Production, Faculty of Agriculture, \\ Tishreen University, Lattakia - SYRIA
}

\begin{abstract}
This study reviews the most important Zoonoses existing in the Arab World. It discusses, the social, economical, and environmental importance of the diseases, including their impact on the trade of agricultural products among the Arab States. The study further deals in more detail, the factors which enhance the spread of the diseases in general, and in the Arab World specifically.

The study presents an evaluation of the existing efforts exerted at national and regional levels to prevent the spread of the diseases and to delimit their negative impacts. Moreover, it tackles the limiting factors facing the preventative measures and efforts exerted to avoid the impact of the diseases. Finally, the study presents recommendations attempting to deal with the weaknesses in the measures taken at national, regional and international levels.
\end{abstract}




\section{دراسة حول الأمراض المشتركة في الإنسان والحيوان والإجراءات المطلوبة

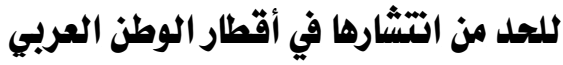

\section{الدكتور/ رفيق جبيل جبلاوي}

أستاذ علم الأوبئة والأمراض المعدية والمشتركة - قسم الإتتاج الحيواني - كلية الزراعة

$$
\text { جامعة تثرين - اللاذقية - سورية }
$$

تتحدث هذه الدراسة عن أهم الأمر اض المشتركة في الإنسان والحيوان الموجودة في أقطار

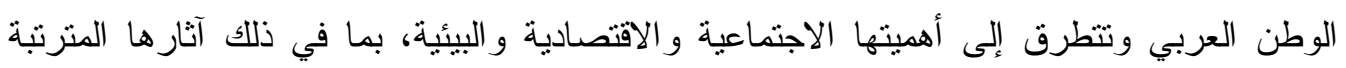
على التجارة الزر اعية البينية العربية.

وتتعرض بشيء من التفيل للعوامل المساعدة على انتشارها بشكل عام وفي أقطار

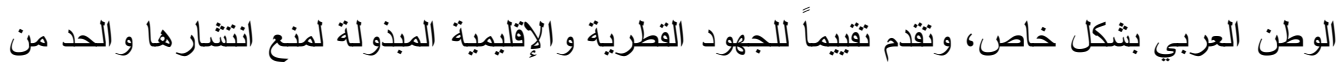
آثار ها السلبية.

وتتطـــرق إلــى المعــوقات و الــلبيات التــي تجابه منع انتثار ها و الحد من تأثثير اتها وتقدم بعض المقترحات لمعالجة القصور على المستوى القطري و الإقليمي و الدولي.

\section{INTRODUCTION مقدمة}

تــو اجه الثــروة الحيو انبة في الوطن العربي ظروفاً صحية تؤثر سلباً على إمكانيات

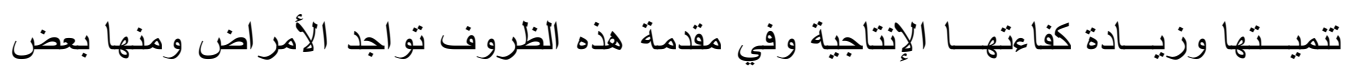
الأمر اض المشتركة التي لا يمكن تجاهل مدى أهميتها في الصحة الحيوانية من جهة و الصحة العامــة مــن جهــة أخــرى مثل: مرض الإجهاض المعدي، السل البقري، الجمرة الخبيثة، الـــلمونيلا، داء البــريميات، داء الكلــب، القراع، داء الكيسات المائية، داء المقوسات، داء الوريقات الكبدية و الدودة الثريطية العز لاء و غير ها. 
ورغــم الجهــود المبذولة من قبل الدول العربية والمنظمات الإقليمية و الدولية لمكافحة هـــهـ الأهـر اض عـن طــريق الإجــر اءات الوقائــية و العلاجية ووضع الضوابط و اللوائح و التـشريعات التي تحد من انتشار هذه الأمر اض إلا أن الثروة الحيوانية في الوطن العربي ما

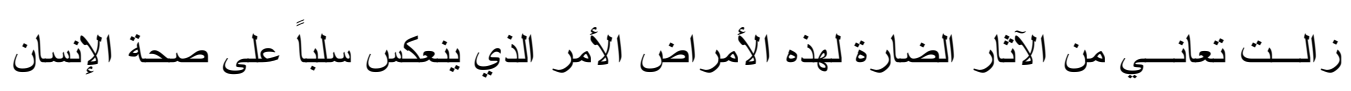
العربي.

ولهـــــــان الــوطن العربي يمثل وحدة جغر افية متكاملة ويقع في قلب العالم وضمن

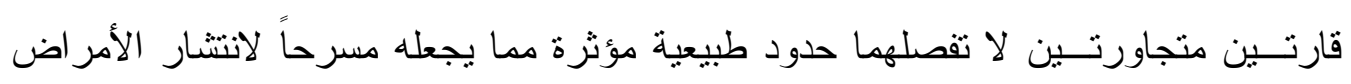
الوبائية الحيو انية و المشتركة. كانت طرق استير اد الحيو انات و المنتجات الحيو انية متثابهة في أغلـب الأقطـار العربية فإن خريطة الأمر اض الوبائية الحيو انية و أغلب الأمر اض المشتركة المسنوطنة والو افدة تكاد تكون منماتلة في كافة أقطار الوطن العربي. إن اســتمرار هـــه الأمر اض في أكثر الأقطار العربية رغم الجهود التي بذلت وتبذل لمحاربـتها و التخفيف من حدتها يفرض على الأقطار المعنية بذل المزيد من الجهود و التفكير في إعداد دراسات هامة لمعرفة ددى انتشار ها وتقييم آثار ها الاقتصادية والصحية.

\section{تعريف الأمر اض المشتركة Definition of Zoonoses:}

بطلـق تعريف الأمر اض المشتركة (Zoonoses) على الأمر اض التي تصيب الإنسان

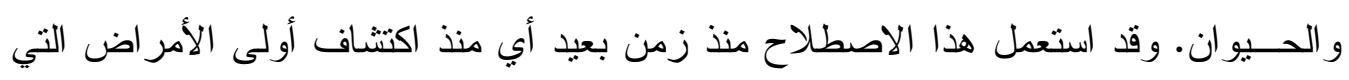

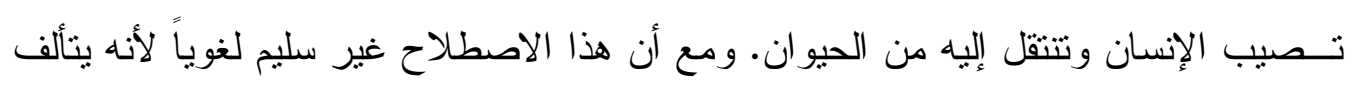

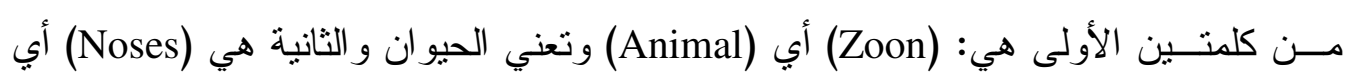
وتعني المرض أي أن ترجمة الاصطلاح تعني (أمراض الحيوان). و على الرغم Kafrelsheikh Vet. Med. J. Vol. 7 No. 1 (2009) 
مـن ذلــك فــإن منظمة الصحة العالمية (WHO) توصي باستعماله كاصطلاح عام ووحيد للأمــر اض التي تصيب الإنسان و الفقاريات الأخرى كونه يخلق أرضية مشتركة بين الأطباء البيطــيين و البــشريين على السو اء للكثتف عن الأمر اض التي تتنقل للإنسان من الحيوانات المستأنسة و البرية ثم لاستخلاص الطرق الكفيلة بالوقاية منها ومكافحتها.

\section{تصنيف الأمراض المشتركة Classification of Zoonoses:}

جرت محاو لات كثثرة لتصنيف الأمر اض المشتركة وعلى الرغم من ذلك فإنه لا يوجد

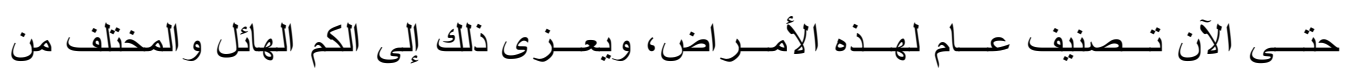
الموضــوعات الو اجب تصنيفها من جهة أخرى. فبعض الباحثين يصنفون هذه الأمر اض تبعاً

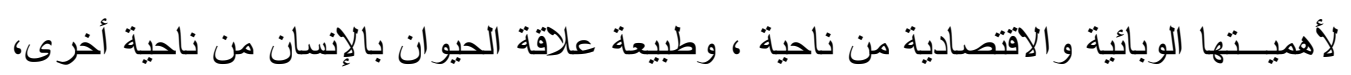

$$
\text { ضمن أربع مجمو عات هي: }
$$

- أمر اض مشتركة بين الإنسان والحيوانات المستأنسة المنتجة كالأبقار والأغنام والماعز و الجمال و الدو اجن. و هذه الأمر اض تؤدي إلى إحداث خسائر كبيرة في الحيو انات و إنتاجها من لحم وحليب وبيض وغيره منل: مرض الحمى القلاعية، الإجهاض المعدي أو البروسيلة وشبه طاعون الدجاج وغير ها.

- أمر اض مشتركة بين الإنسان والحيوانات المستأنسة غير المنتجة كالكلاب و القطط، وطيور الزينة والنسانيس وغيرها، ويكون الأثر الاقتصادي لهذه الأمراض أقل أهمية مما بصيب الحيونات المنتجة منل : داء البريميات، الحمى الببغائية، داء المقوسات

$$
\text { الغندية و غير ها. }
$$

- أمر اض مشتركة بين الإنسان و الحيوانات غير المستأنسة التي تعيش في بيئته كالجرذان و الفئر ان. وتكون هذه الأمر اض أحياناً ذات آثار وبائية و اقتصادية كبيرة بصعب مكافحتها وتؤدي إلى خسائر مادية ومعنوية جسيمة منل: مرض الطاعون وداء البريميات. 
- أمر اض مشتركة بين الإنسان و الحيو انات البرية كالغز لان و الثغالب و الذئاب. وتختلف آثار هذه الأمر اض و أهميتها وفق الموقع الجغر في وعدد الأفر اد الذين يصابون بتلك الأمر اض

$$
\text { سنوياً متل : داء الكلب و غير ها. }
$$

وقد صنفت منظمة الصحة العالمية عام 1962 الأمر اض المشتركة حسب طبيعة دورة

$$
\text { حياة العامل المعدي ضمن أربع مجموعات هي: ولي }
$$

• أمراض مشتركة مباثرة: وهي الأمر اض الني تنتقل من الحيوان إلى الإنسان عن طريق الاتصال المباثر بينهما مثل : مرض الجمرة الخبيثة و السل.

أمر اض مشتركة ذات دورة متكاملة: وهي الأمر اض التي تحتاج مسباتها إلى قضاء فترة تطور معينة في الحيوانات والإنسان لاستكمال دورة حياتها مثل: أمراض الديدان الثريطية العز لاءو والمسلحة وداء الكيسات المائية.

• أمر اض مشتركة بيولوجية : وهي الأمر اض التي تنتلل من الحيو انات إلى الإنسان حيوياً بواسطة حامل غير فقاري مثل : الطاعون و الليشمانيا ومرض النوم الإفريقي و الأمراض الفيروسية المنقولة بالحشر ات متل: مرض حمى الو ادي المتصدع و غيرها. • أمراض مشتركة رمية: وتمثل الحيوانات فيها مصدر العدوى ومستودعه، إلا أن الإصابة بهذه الأمر اض لا تتم إلا عن طريق انتقال مسبباتها من الوسط الخارجي (التربة، المياه، الأعثاب... الخ) متل: مرض الكزاز، و التسمم الوشيقي.

وقــد صنفها الباحث كروماثيفسكي عام 1965 نبعاً لآلية انتقالها بين البشر إلى ثلاث

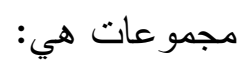

Kafrelsheikh Vet. Med. J. Vol. 7 No. 1 (2009) 
المجمــوعة الأولــــ: وتتشل الأمر اض التي تتميز بأن آلية انتقالها من الحيوان إلى الإنسان يمكـن أن تـتحقق بـسهولة بين إنسان وآخر مثل : الأمر اض الفطرية

$$
\text { الجلدية، السل الرئوي و الحمى الصفر اء وغير ها. }
$$

المجمــوعة الثاتـية: وتـــم الأمر اض التي نتتقل بسهولة من الحيوان إلى الإنسان ، إلا أنه يصعب أو يندر انتقالها من إنسان إلى آخر مثل: مرض الجمرة الخبيثة،

$$
\text { البريميات و غير ها. }
$$

المجمــوعة الثالــثة: وتضم الأمر اض التي لا يمكن أن تتنقل من إنسان إلى آخر مثل: حمى عضة الجرذ، داء الكلب وقسم كبير من أمر اض القر اد وغير ها.

وقد ألحقت منظمة الصحة العالمية في عام 1967 تصنيفها السابق بتصنيف آخر يتعلق

$$
\text { بدور العائل الخازن للمرض ويضم الآتي : }
$$

• أمر اض مشتركة حيوانية بشرية: وهي الأمر اض التي يقوم الحيوان بدور العائل الخازن لها، وتتنقل منه إلى الإنسان مثل: مرض الجمرة الخبيثة، الرعام و البريميات و غيرها. أمر اض مشتركة بشرية حيو انية: ويقوم الإنسان بدور العائل الخازن لها وتتنقل منه إلى الحيو ان منل مرض الحمى القرمزيه، الدفتيريا، شلل الأطفال وغيرها. أمر اض مشتركة ثثائية الوجهين: وتصيب الإنسان و الحيو ان بدرجات منساوية وتتنقل من أي منها إلى الآخر منل مرض السل و غير ها.

ويمكـن تـصنيف الأمر اض المشتركة وفق العامل المسبب لها في ست مجموعات رئيسية هي: 
الأمر اض الجرثومية المشتركة: مثل مرض الجمرة الخبيثة ، البروسلية، السل، البريميات و التيفوئبد و الر عام و الطاعون و غيرها. وهي أمر اض تؤدي إلى انخفاض النشاط الحيوي للإنسان وقد تؤدي إلى وفاته أحياناً.

الأمر اض الفيروسية المشتركة: مثل داء الكلب والحمى القلاعية وحمى الوادي المتصدع وحمى القرم الكونغو النزفية وغيرها، وتؤدي إلى خسائر اقتصادية فادحة في الحيوانات ووفاة العديد من الأشخاص.

الأمراض الريكتسية المشتركة: مثل مرض الحمى المجهولة ومرض التيفوس الفأري الريكتسي ومرض الجدري الريكتسي.

الأمر اض الفطرية المشتركة: مثل مرض السعف، داء الرشانشيات وداء النوسجات وغيرها. الأمر اض الطفيلية المشنركة مثل: داء الليشمانيا، المقوسات الغندية، مرض النوم الإفريقي، البابيزيا، داء الوريقة الكبدية، داء الثعرنيات، الكيسات المائية و الثريطيات. الأمر اض المشتركة التي تسببها بعض أنواع شعبة مفصليات الأرجل منل : داء الجرب

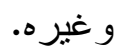

• أمر اض البريون: ويمكن إضافة مجموعة أخرى تحت اسم أمراض البريون وتضم مجموعة من الأمر اض الخطيرة التي تصيب مجموعة من الحيوانات والإنسان وتؤدي إلى إلى اعتلال الدماغ الإسفنجي منل مرض جنون البقر . طرق انتقال الأمر اض المشتركة:

الملامسـة: ســـواء أكانت مباشرة أم غبر مباشرة مع الحيو انات المريضة أو منتجاتها أو

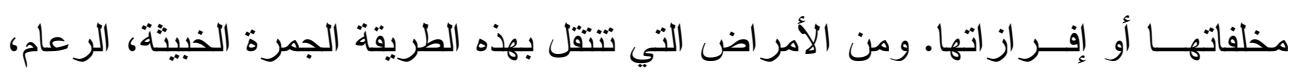
البروسيلا، الليستريا وداء البريميات و غيرها.

Kafrelsheikh Vet. Med. J. Vol. 7 No. 1 (2009) 
Jeblawi, $R$.

• الاستنشاق: كما هو الحال في مرض السل.

•الابتلاع: عن طريق تلوث أغذية الإنسان ببراز الحيوانات المريضة أو الحليب الملوث. • العدوى المحمولة بواسطة الحشرات: مثل حمى الو ادي المتصدع وداء الليثمانيا و غير ها. ه العدوى عن طريق تلوث الجروح العرضية: في هذه الحالة تدخل العو امل المسببة للمرض إلى أنسجة الإنسان بالطرق التالية : - عض الحيو انات: مثل داء الكلب وحمى عضة الجرذ. - تلـــوث الجــروح بالجــر اثثم أو بذيــرات الأنو اع الحيو انية المنشأ منتل داء الثعريات

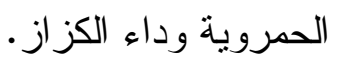

الأهمية والآثار الاجتماعية والاقتصادية والبيئية للأمراض المشتركة والآثار المترتبة على التجارة الزراعية البينية العربية:

تبــرز الأهــــة الاجتماعـية للأمر اض المشتركة في كونها تعرض صحة الإنسان

للخطــر • وبحسـسب معطيات لجنة خبر اء الأمر اض المشتركة لمنظمـــة الصحـــة العالميــة هناك ما يزيــــــــى (273) مليون إنسان من سكان دول حوض الكاريبي مهددين بخطــر الإصــابــة بعدوى أكـثر مــن (150) مرضـاً مشتركاً. ويرجح إصـابة (185) مليون إنسان بإحدى هذه الأمر اض خلال فترة حياتهم. ويعالج في أمريكا سنوياً حو الي (175) ألف إنسان ضـــد داء الكلب بسبب تعرضهم للعض من قبل الحيو انات البرية اللاحمة ويموت منهم سنوياً مــا يزيد عن (300) إنسان. وتم في أوروبا خلال الفترة الواقعة ما بين أعوام 1972-1976 تـشخيص (82) ألـــ حالـــة إصــابة بهذا الداء في الحيو انات وسجل موت (621) إنسانا،

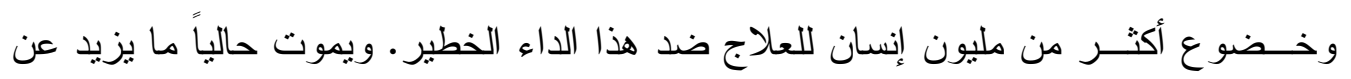
(15) ألف إنسان سنوياً بسبب هذا المرض. مليون إنسان

$\overline{\text { Kafrelsheikh Vet. Med. J. Vol. } 7 \text { No. } 1 \text { (2009) }}$ 
ويـشكل كثير من الأمر اض المشتركة المكتثفة سابقاً أو حالياً معضلة صحية كبيرة

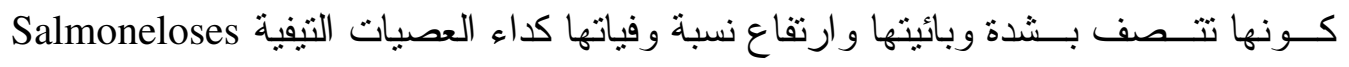
و البروسـيلا Brucellosis و الــتهابات الــدماغ الفيروســـية وعدوى مسيبات التنسم الغذائي

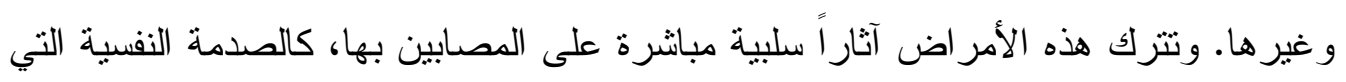

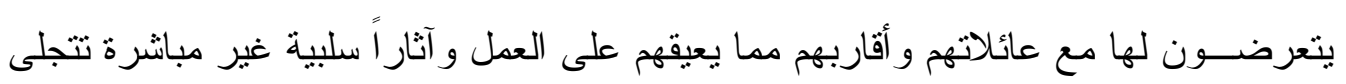
في سوء نوعية المنتجات الغذائية الحيو انية وقلتها، مما يؤدي إلى حرمان المو اطنين وخاصة الأطفــال من الحصول على البروتين الحيو اني اللازم لنمو هم مما يعرضهم للضعف و الهزال

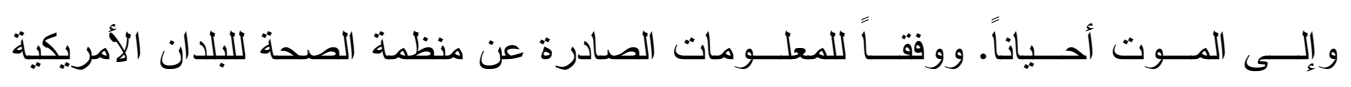
(PAHO) (53.2 \% مـن الأطفــال بعهـر 5 ســنوات في دول هذه المنظمة يعزى إلى سوء نوعية المنتجات الغذائية الحيو انية وقلة كميتها.

وتؤثــر الأمر اض المشتركة نأثيراً مبانشراً على النتمية الاقتصادية الوطنية حيث أنها

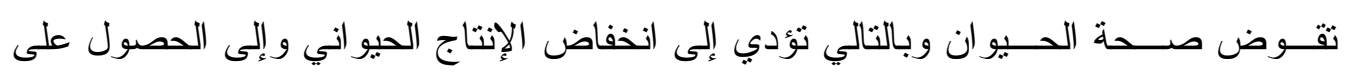

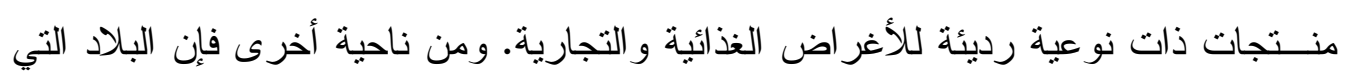

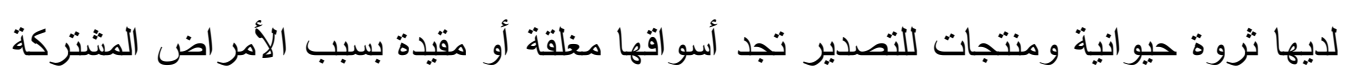

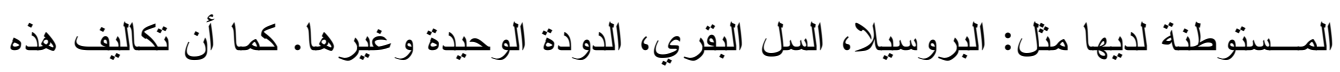

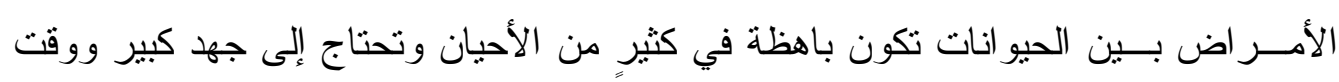

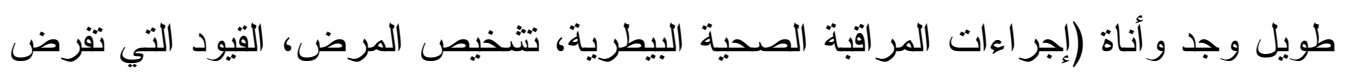

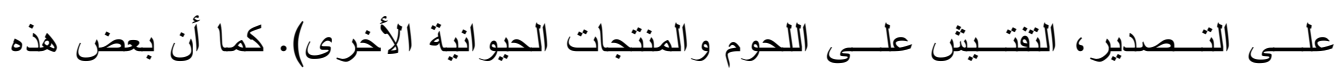

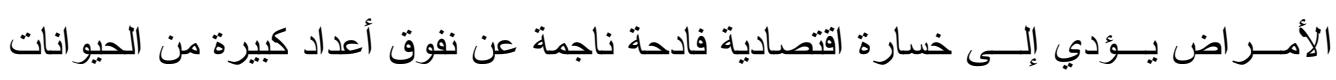


Jeblawi, $R$.

المــصابة وخاصـــة الأمسـر اض المشتركة التي تصيب الحيو انات الفتية وحديثة الو لادة و التي تتز افق بنسبة نفوق عالية. أما الحيوانات التي تبقى على قيد الحياة فتتصف بضعف الخصوبة وضــف المقـدرة على العمل. ومن ناحية أخرى فإن تكاليف فحص ومعالجة الإنسان الذي يكــون قد تعرض للإصـابة بأحد الأمر اض الحيو انية المشتركة مثل البروسيلا أو حمى الوادي المت صدع أو حمى القرم الكونغو النزفية لمنع إصـابة الناس بهذه الأمر اض قد تكون مرتفعة وباهظة التكاليف إضافة إلى الأعباء المالية الناجمة عن ضرورة التخلص من جثث الحيوانات النافقة بسبب هذه الأمر اض عن طريق دفنها أو حرقها.

و انتشار الأمر اض المشتركة في أقطار الوطن العربي يؤثر بشكل سلبي على التجارة

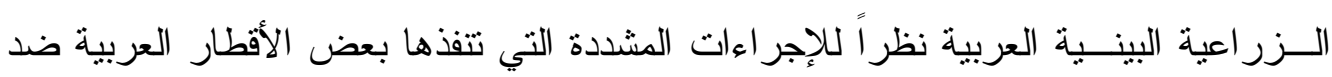
بعــضها الآخــر ـ كـــا هـــو الحال في تشدد دول الخليج في عملية استير اد الأغنام و الماعز ولحــومها من السودان و الصومال بسبب وجود مرض البروسيلا في هذه الأقطار لدرجة أن أي إرســالية من هذه الحيو انات قد تعاد إلى بلد المنشأ إذا ثبت أن حيو اناً واحداً أعطى نتيجة مــصلية إيجابية لهذا المرض على الرغم من أن مرض البروسيلا معروف وموجود في كافة

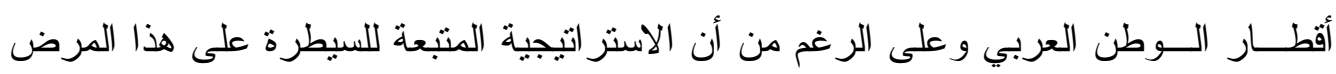
هي و احدة في أغلب الأقطار العربية.

ومسن الناحسية البيئية فإن الأمر اض المشتركة تحتل أهمية خاصة فهي عامل مؤثر

بسشكل مباشر أو غير مباشر على حيو انات الطبيعة وكثاهد على ذلك نذكر التغيرات البيئية المسـسلة فـي بعض مناطق العالم و المتعلقة بتتفيذ إجر اءات صـارمة في مكافحة بعض بؤر العـدوى الطبيعية للأمر اض المشتركة كمكافحة مرض سعار البراري الذي أدى إلى الإقلال مـن عـدد سلالات الثعالب في بعض البلدان الاوربية مما ساعد على زيادة أعداد الحيوانات لبرية وبخاصة القوارض التي تسببت في خسائر اقتصادية كبيرة للمحاصيل الزر اعية. 
العـوامل المسساعدة على انتشار الأمراض المشتركة بشكل عام وفي أقطار الوطن العربي بشكل خاص:

يمكـن أن بتعرض للإصـابة بهذه الأمر اض أي إنسان دون أي اعتبار لسنه وفي أي وقــت كان وحيثما وجد. ففيما يتعلق بالأمر اض المشتركة التي تتنقل عن طريق الغذاءو التي تلعــب العادات الغذائية دوراً كبيرًا في انتشار ها فليس هنالك إنسان غير معرض بالإصابة بها و الالــيل علــى ذلك إصابة الناس بهذه الأمر اض بسبب تتاولهم للطعام غير المطبوخ جيداً أو غيــر المطهــــــــى الإطلاق تشكل ظاهرة كثيرة الحدوث. وفي هذا السباق نتكل اللحوم و الحلـيب ومشتقاتها و البيض و الحلويات غير المطهية جيداً خطر اً كبير اً على صحة الإنسان. فاللحوم ومنتجاتها غير المطهية يمكن أن تسبب للإنسان أمر اض: الجمرة الخبيثة، السلمونيلا، داء المقوســات الجنينـية، البريميات، الأمر اض الناجمة عن المسبيات الجرثومية اللاهو ائية و الأمــر اض الــناجمة عـن الذيفانات الجرثومية (التسمم الوشيقي، (Clostridial diseases) التـسمم بذيفانات المكورات العنقودية والمعوية) وعن طريق تتاول الحليب غير المغلي جيداً يمكـن الإصـابة بأمر اض: السل، البروسيلا، الدوران، السلمونيلا، الحمى القلاعية والأكزيما السارية وغيرها. ومن خلال تتاول الإنسان للبيض يمكن أن يصاب بالسلمونيلا وخاصة عن طــريق بيوض الطيور المائية التي غالباً ما تكون محملة بأنواع خطيرة من العصيات التنفية، ولذلك لا تستعمل منل هذه البيوض في صناعة الحلويات. وعن طريق المياه الملوثة بمسبيات المــر اض المـشتركة التــي تطــرحها الحيو انات بمكن أن بصـاب الإنسان بأمر اض: الحمى القلاعــية، الجمـرة الخبيثة، البريميات، الدوران، الرعام، السلمونيلا، الإكزيما المعدية، داء العصيات المقوسة الجنينية وداء العصيات القولونية و غير ها. 
Jeblawi, $R$.

وقــد صــنفت منظمة الصحة العالمية عام 1976 الطفيليات التي ترتبط بالغذاء إلى

مجمو عتين:

الأولـــى: تــضم طفيلــيات تعــيش أطــــوار ها المعدية في الغذاء منل اللحم، السمك، القو اقع، القنريات كداء المقوسات الغندية و الدودة الوحيدة.

الثاتــية: تــضم طفيالــات توجد أطور ها المعدية كملوثات للغذاء ومصدر العدوى يوجد في الوســـ الخارجـي مــتل: المــاء، التربة، الحيو انات. كداء الأكياس المائية وداء المقوسـات الغندية (الكيسات البيضية .Ocysts) وتتنقل هذه الأمر اض إلى الإنسان

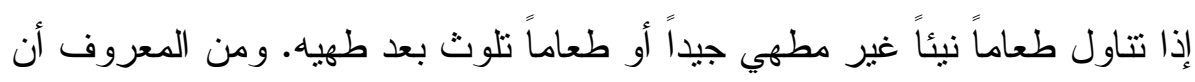

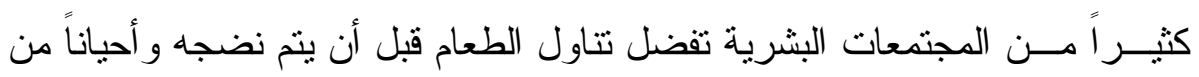
دون طهـي علـى الإطلاق. ومما يزيد من انتشار هذه الأمر اض تغذية الحيوانات بمـتل هذه الأطعمة كإطعام اللحوم النيئة المصابة بالكيسات المائية للكلاب و إطعام اللحوم النيئة المحتوية على طفيلي المقوسات الغندية للقطط. كما أن نقل الطعام من مكــان إلـى آخــر ومن دولة إلى أخرى بتقنيات تخزينية غير متطورة واستعمال مخلفات الإنسان و الحيوان في تغذية بعض الحيوانات يساعد على انتشار الأمر اض الطفيلــية، وإن عــدم الــرقابة الصحية على عملية إنتاج بعض الأغذية تساعد في انتشار بعض الأمر اض المشتركة.

وهـــاك الكثيــر مــن المناسبات الدينية والأعياد والأعر اس و المآتم التي تذبح فيها الحـيو انات من دون رقابة بيطرية في العديد من دول العالم وخاصة ذبح الأغنام و الأبقار في بلـــدان العــالم العربــي و الإسلامي، وذبح الخنازير في بلدان أخرى من العالم قد يؤدي إلى إصــابة الإنـسـان بالــدودة الوحيدة وداء الثعرينات وحمى الو ادي المتصدع و إصـابة الكلاب بالــدودة المـشوكة الحبييــية (دودة الأكــياس المائية). وقد يتعرض الإنسان لخطر الإصـابة Kafrelsheikh Vet. Med. J. Vol. 7 No. 1 (2009) 


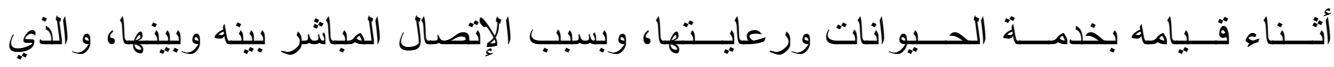

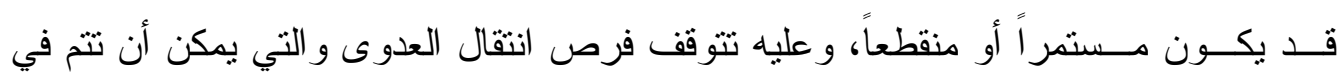

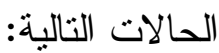

1- نتيجة تعرض الإنسان للعض من قبل الحيوانات المريضة أو الحاملة للعدوى منل داء الكلب، البستوريلا Pasteurellosis، حمى عضة الجرذ وغير ها.

2- أثناء قيام المربين بتتظيف الحيوانات وتعليفها وحلبها وتتظيف الحظائر وقيام الفنيين

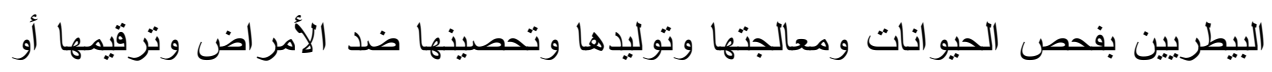

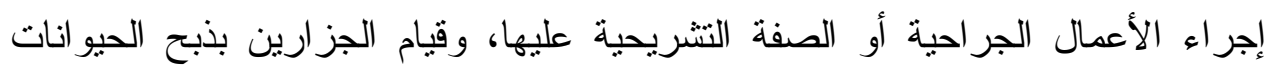

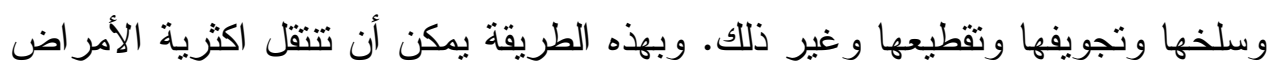
المشتركة إلى الإنسان مثل: الجمرة الخبيثة، البروسيلا، الدوران، الرعام، الوزمة

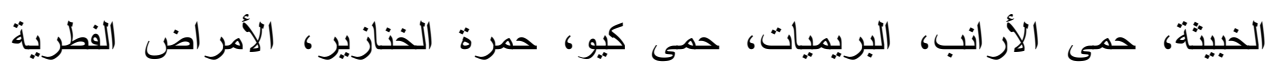
الجلدية، داء المقوسات الغندية، الكيسات المائية، وغيرها. ومما يساعد على انتقال هذه الأمر اض وجود الجروح و الخدوش و التشققات في الأيدي أو في أجزاء الجسم الأخرى. يتبين مما تقدم إمكانية تعرض بعض العاملين في مجالات معينة للإصابة بالأمر اض

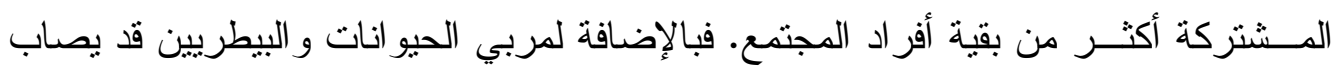
العاملـين بتـــنيع المو اد الغذائية ذات الهصدر الحيو اني (ذبح الحيوانات، سلخها، تجويفها، نزع العظم، تصنيع الجلود، الصوف، العظام، الثعر .... وغيرها)، بكثير من الأمر اض مثل حمــرة الخنازيــر، داء المقوســات الغــدية، كما يتعرض العاملون في المختبرات للإصـابة

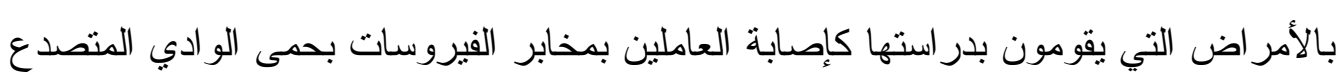
و إصابة العاملين في مخابر الأوليات باليشمانيا وداء المقوسات الغندية. وتعد بعض الأمراض Kafrelsheikh Vet. Med. J. Vol. 7 No. 1 (2009) 
Jeblawi, $R$.

المشتركة أمر اضاً خاصةً بأصحاب بعض المهن كالشكل الرئوي لمرض الجمرة الخبيثة الذي يعــد مرضــاً خاصاً لعمال دباغة الجلود وتصنيع الصوف وداء البيغائية للعاملين في تصنيع الــريش و الــز غب، ومرض عجيرات الحلاب لعمال الحلابة، ومرض حمرة الخنازير لعمال المسالخ و عمال تصنيع الأسماك. وكثير اً ما يصاب صبادو الحيو انات البرية أثثاء قيامهم بسلخ جلود الحيو انات وفتح جثثها خاصة في حالة وجود جروح أو شقوق أو خدوش أو تشققات في أيـــيهم بالأمــر اض التالـــية: حمى كيو، حمى الأرانب، البروسيلا، الطاعون، الدوران. كما يتعـرض السياح منسلقو الجبال ومحبو الطبيعة وهواة جمع النباتات البرية و الأعثاب الطبية و غيـر هم للإصـابة ببعض الأمر اض المشتركة بسبب تعرضهم للسع من قبل بعض مفصليات الأرجل مثل: مرض كياسانور، حمى كيو، حمى المتوسط، حمى نثيكونكونيا، التهاب الدماغ و الــنخاع الثوكي الفيروسي في الخيول، التهاب الدماغ والنخاع الثوكي في الأغنام، الحمى الصفر اء، حمى الو ادي المتصدع و غير ها.

وممــا يـسـاعد علــى انتشار الأمر اض المشتركة استعمال مياه المجاري في سقاية المزروعات واستعمال مرسباتها غير المعالجة جيداً أو البراز نفسه في تسميد المحاصيل التي تــؤكل مــن دون طهـي. كذلك فإن الكميات الكبيرة من نفايات الحيو انات الناتجة عن أماكن

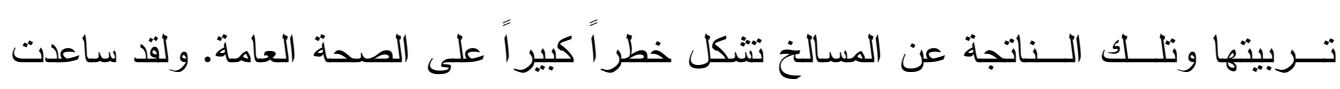
وسائط النقل الحديثة في عودة الإنسان المصاب إلى بلده بسر عة في أب منطقة في العالم أثناء

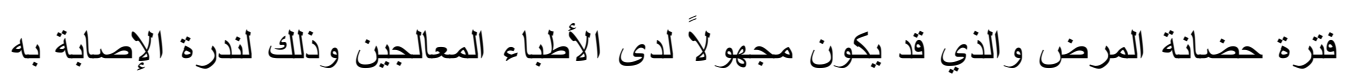
بــين مواطني هذا البلد مثل: داء النوم اللإفريقي، الملاريا، كثير من الديدان الطفيلية. كما قد يؤدي نقل بعض الحيو انات البرية من موطنها الأصلي إلى حدائق الحيو انات إلى نقل أمر اض طفيلية أو غير طفيلية غريبة إلى الإنسان. 
إن العلاقات الاقتصادية الحيوية بين دول العالم وخاصة فيما يتعلق بعمليات استنيراد وتــصدير الحيو انات الحيوية ومنتجاتها، وتجارة تهريب اللحوم، وعو امل أخرى كانت السبب فـي الاتتـشار الجغر افي الو اسع للعديد من الأمر اض والتي من ضمنها الأمر اض المشتركة. فكتيــر مــن الأمر اض التي كانت خاصة بدول أمريكا اللاتينية أو الأفريقية أو الأسيوية مثلاً انــتقلت إلـى اوربـــا ويمكن لغير ها من الأمر اض أن تتتقل وتهدد الإنسان و الحيو ان في هذه القارة كمرض حمى الوادي المتصدع، اللسان الأزرف، طاعون الخنازير الأفريقي، البروسيلا المتـسببة بالعتــرة المالطية، التهاب الدماغ الفنزويلي في الخيول، الحمى النزفية الأرجنتينية، الطفح الحويصلي الجلدي، وعترات جديدة من فيروس الحمى القلاعية وغيرها.

ووفقــاً لمعطـيات المكــتب الدولي للأوبئة الحيوانية (OIE) ومنظمــة الأغذيــة

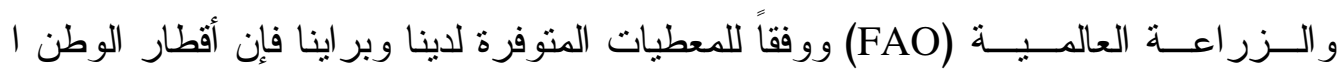
لعربـي تعد من أكثر الدول تعرضاً لاخول مصادر عدوى الأمر اض المشتركة من الخارج. وقــد سجل وجود العديد من هذه الأمر اض في حيو انات المنطقة العربية والأقطار المجاورة نذكــر منها: مرض السل البقري، داء السلمونيلات، داء البروسيلات، داء البريميات، الجمرة الخبيـثنة، الدوران، التسمم الوشيقي، الكزاز، القر اع، داء الكلب، الحمى القلاعية، حمى القرم الكونغـــو النزفية، حمى غرب النيل، حمى الوادي المتصدع، الإكزيما السارية، الجدري، شبه طاعون الدجاج، داء المقوسات الغندية، داء الليشمانيات، مرض النوم الإفريقي، داء الوريقات الكبدية، الكيسات المائية، الثريطيات، الدودة الحلزونية. وكل هذه الأمر اض تم التعرف عليها و التبلــيخ عــنها علـى عـدة مستويات وفي عدة مناسبات ويعزى سبب وجود و انتشار هذه الأمر اض في المنطقة العربية و الأقطار المجاورة إلى ما يلي: 
Jeblawi, $R$.

1- الموقع الجغر افي المتميز للوطن العربي فهو يمثل وحدة جغر افية متكاملة ويقع في قلب العالم ضمن قارتين متجاورتين لا تفصلهما حدود طبيعية مؤثرة مما يجعله مسرحاً لانتشار الأمر اض الوبائية الحيو انية ومنها الأمر اض المشتركة .

2- الحدود الطويلة المشتركة للأقطار العربية مع بعضها البعض ومع الدول المجاورة والتي هي يصعب مر اقبتها وتحديد حركة قطعان الحيو انات عبر ها.

3- عمليات تهريب المو اشي التي لا تخضع لأي رقابة صحية بيطرية وهذا الأمر متفني في كل الأقطار ذات الحدود المشتركة.

4- الانتقال الحر للحيوانات وخاصة الأغنام والإبل داخل الأقطار العربية وبين الأقطار المجاورة بسبب المساحات الثاسعة لبعض الأقطار كالسودان والجزائر وليبيا ومصر و السعودية و اليمن و العر اق وصعوبة السبطرة على تلك التحركات. 5- اضطر ار الحيوانات أثناء فترات التصحر و الجفاف التي حصلت في بعض الأقطار العربية خلال الثمانينات وخاصة الأغنام والجمال إلى البحث عن الكلأ و الماء في أماكن لم تردها من قبل الأمر الذي أدى إلى اختلاطها مع أنواع أخرى من الحيو انات المصابة أو الحاملة لمسببات بعض الأمراض المشتركة كما حدث في السودان و الصومال وموريتانيا . 6- التجارة القطرية و الدولية و هي تصدير و استير اد الحيو انات ومنتجاتها ومخلفاتها وبخاصة الأبقار و الأغنام في ظل غياب القوانين البيطرية الصحية الصارمة . 7- الكثافة العددية للعمالة الأجنبية في بعض الأقطار العربية كدول الخليج العربي

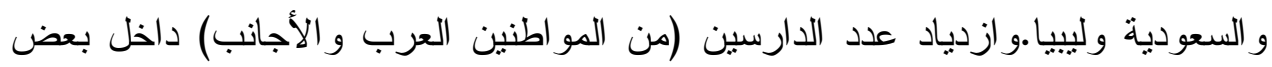
الأقطار العربية كمصر و سوريا ، وزيادة عدد المواطنين العرب الدارسين و المغتربين خارج العالم العربي وازدياد عدد السواح في بعض الأقطار العربي ، وهذا كله يؤدي إلى انتقال الأمر اض المشتركة و انتشار ها . 
8- عدم وجود الكادر الفني ومراكز الأبحاث المتخصصة بتشخيص وعلاج الأمراض

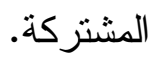

9- انتشار بعض الحيوانات البرية التي تحمل العديد من مسببات الأمراض المشتركة كالحمى القلاعية وداء الكلب والبروسيلات في مناطق تربية الحيوانات الزراعية وبخاصة مناطق تربية الإبل والأغنام ونحركها في نفس اتجاهات تحركات هذه الحيوانات كما هو الحال في الصومال و موريتانيا والسودان. المعوقات والسلبيات التي تجابه منع انتثار الأمراض و الحد من تأثيراتها إن مــن أهــم المعـوقات والـسلبيات التـي تجابه منع انتتـار الأمر اض الحيوانية

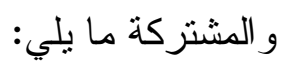

تنني الخدمات البيطرية بكافة أوجهها سواء الوقائية أو العلاجية أو النتخيصية ، مما جعل الأمر اض الحيو انية ومنها بعض الأمراض المشتركة تستوطن في كثير من مناطق العالم العربي وتفتلك بالثروة الحيو انية .

• ظهور عترات جديدة لمسببات الأمراض الحيوانية النقليدية معندة على طرق الدقاومة التقليدية المتوفرة في الأسواق المحلية للأقطار العربية .

قلة الدعم الذي يقدم للبحوث في مجال الصحة الحيوانية وقلة عدد العاملين في مجال

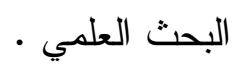

قلة الأيدي العاملة المدربة و الماهرة في مجال العناية بالحيوانات وتربيتها بحسب الأصول العلمية المتعارف عليها مما جعل التعامل مع الحيوان يتم بطرق بدائية وتشاء معاملته

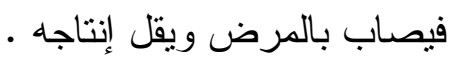


Jeblawi, $R$.

التجارة الدولية الحرة بالحيو انات جعل تتقل الحيوانات من المناطق الغنية بها إلى المناطق الأخرى أسهل وأسر ع و هذا ما قد يتسبب أيضاً في دخول الأمر اض و انتشار ها .

عدم كفاية المحاجر البيطرية وضعف إمكانيات الموجود منها و الحدود المفتوحة بين الدول الأمر الذي أدى إلى التنقل العشو ائي للحيو انات دخو لاً وخروجاً إلى داخل المناطق العربية أو تهريبها وفقاً لتنبذب أسعار ها أو استخدام مناطق الرعي المشتركة بين الدول العربية أو بينها وبين الدول المجاورة لها مما قد يتسبب في دخول الأمر اض وانتشار ها ـ ضعف البنية التحنية من طرق زر اعية ومو اصلات وكهرباء وهاتف في كثثر من المناطق الريفية مما ترتب عليه مشقة نقل الحيوانات من مكان إلى آخر أو صعوبة تقديم الخدمات لها سو اء الغذائية أو البيطرية أو النقل أو حتى الابلاغ عن الأوبئة الحيو انية مما يؤدي إلى حدوث كوارث في الثروة الحيو انية.

عدم وجود مختبرات تتخيصية كفوة لكافة مجالات الأمر اض الوبائية ومسبباتها لكل دولة عربية وغياب المتخصصين في مجالات نتخيص هذه الأمر اض في معظم أقطار الوطن العربي.

غياب المختبرات المرجعية التشخيصية التي يمكن اللجوء إليها و المعتمدة دولياً في العالم العربي. مما يضطر الدول العربية إلى اللجوء إلى المختبرات العالمية ومختبرات الدول الأخرى في مجال تشخيص الأمراض الوبائية أو الفحوص التأكيدية، الأمر الذي يؤخر عملية التتخيص و اتخاذ القرار ات الخاصة بمكافحة الأمر اض ويساعد على انتشارها. 
• عدم وجود وحدات للمسح الوبائي حول أوضاع الأمراض والمراقبة الدائمة وتوفير المعلومات لمتخذ القرار وذلك بالقيام بمسوحات دورية في كل قطر بقصد نقييم الأوضاع الوبائية التي هي الرديف الأساسي للنتخيص و السيطرة على الأمر اض. • عدم توفر نظام معلومات بيطري للتقصي عن الأمراض وعدم توفر وسائل الاتصال الحديثة في بعض الدول العربية.

مقترحات التظوير والتنسيق ومعالجة القصور على المستوى القطري:

1- تحسين أداء خدمات الصحة الحيو انية ومكافحة الأوبئة لتصبح نظاماً خدمياً ذات كفاءة عالية في التعرف على الأمر اض الحيو انية المشتركة ومسحها و السيطرة عليها. 2- تحسين وتدعيم المحاجر البيطرية حتى تقوم بدورها في منع دخول الأمر اض المشتركة

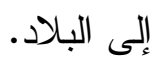

3- تطوير أداء المختبرات البيطرية لتصبح جزءاً من الخدمات البيطرية منصلاً ومتلازماً مع نثاط الاستقصاء و المسح و السيطرة على الأمر اض المشتركة. 4- دعم معامل إنتاج اللقاحات بتخليصها من البيروقراطية الحكومية وتقويمها لتصبح مؤسسات إنتاجية ذاتية التحويل والاستمرارية في إنتاج يطابق المواصفات العالمية لتلك المنتجات وتحويل إدارتها للقطاع الخاص حسب خطة مدروسة. 5- التأكيد على تدريس مادة الأمر اض المشتركة في كليات ومعاهد الطب البشري و البيطري

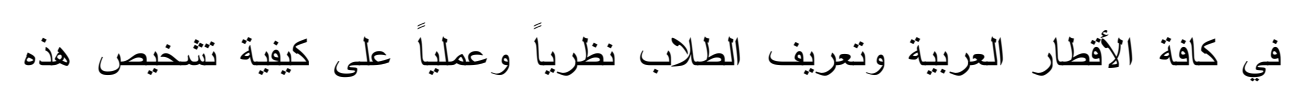
الأمر اض ودر اسة وبائيتها وسبل مكافتنها. 
Jeblawi, $R$.

6- إقامة دورات تدريبية في مجال الحاسوب و البرامج الوبائية للأمر اض المشتركة ووسائل التشخيص الحقلي و المخبري.

7- التعاون الوثيق مع منظمة الصحة العالمية والمركز الدولي للأوبئة الحيو انية ومنظماتها الدولية. وتبادل المعلومات مع الدول المجاورة حول ظهور أي مرض مشترك وتنظيم الإجر اءات المتعلقة بمكافحة هذه الأمر اض و الوقاية منها.

8- أن يكون نتفيذ إجر اءات المكافحة و الوقاية في كل قطر على مسنوى الدولة وبإنثر افها. 9- خلق قاعدة مادية لإيجاد مؤسسات ومعاهد بيطرية بشرية مشتركة ورفدها بالكو ادر الفنية اللازمة و المدربة.

10-العمل على نشر المعلومات و الابحاث الجديدة المتعلقة بالأمر اض المشتركة وتوعية المواطنين بخطورة هذه الأمراض والأضرار الناجمة عن اقتتاء الحيوانات المدللة بالكلاب و القطط و الفسانيس.

11-رفع المستوى المعيشي للسكان مما يؤدي بالتدريج إلى القضاء على عدد كبير من الظواهر غير المرغوب فيها من الناحية الصحية والتي تؤدي إلى إصابة المواطنين بالأمر اض المشتركة.

12-المراقبة الصحية البيطرية الصارمة على كافة أنواع المنتجات الحيوانية المستوردة و المواد الغذائية من مصدر حبواني الداخلة إلى القطر برفقة السياح أو الأشخاص العابرين و إتلاف غير الصالح منها. 
13-تثديد الرقابة الصحية على معامل تصنيع المنتجات الغذائية ذات المصدر الحيو اني و أماكن حفظها وعلى معامل الألبان والأجبان ومحطات تربية الحيو انات وبخاصة تلك

$$
\text { التي تمد هذه المعامل بالحليب ومعامل تصنيع الأعلاف و العاملين فيها. }
$$

14-مساهمة المستشفيات و المستوصفات و العيادات الطبية و البيطرية العامة و الخاصة و المسالخ بالتبليغ الفوري عن الحالات المؤكدة أو المشتبه بها بأنها أمر اض مشتركة.

15-تثديد الرقابة الصحية البيطرية على الحيوانات المستأنسة التي نربى داخل البيوت

$$
\text { و إخضاع أصحابها للكثف الطبي الدوري الاجباري. }
$$

16- المر اقبة الفعلية لاصطياد الحيو انات البرية و الحيو انات التي نذبح بعيداً عن أعين الرقابة البيطرية وبخاصة في القرى و الأرياف.

17-إخضاع معاهد ومحطات البحث العلمي البيطري ومر اكز إنتاج الأدوية واللقاحات و المخابر التي تستخدم المواد المعدية في أعمالها والعاملين فيها إلى رقابة صحية صارمة.

18-معالجة مياه المجاري ونفايات الحيوانات الناتجة عن أماكن تزبيتها وتلك الناتجة عن المسالخ ومعامل دباغة الجلود.

19-مكافحة القو ارض و القضاء عليها أينما وجدت لأنها تحمل العديد من مسبيات الأمر اض الخطيرة التي تتقلها إلى الإنسان.

20-إخضاع المواطنين العرب والأجانب الداخلين إلى القطر ومواطني القطر المغتربين و العائدين من الدول الأخرى للكشف الصحي وبخاصة في فنز ات نشوب الأوبئة. 
Jeblawi, $R$.

\section{على المستوى الأقليمي والدولي:}

1- جمع المعلومات عن الأمر اض المشتركة الموجودة في الأقطار العربية المختلفة وإنشاء شبكة أو قاعدة معلومات إلكترونية ثابتة عنها في مركز يتم تحديده على مستوى المنطقة العربية من خلال برنامج خاص بالمسوحات الميدانية للأمر اض المشتركة تشارك فيه مر اكز الأبحاث البيطرية والبثرية في الدول العربية وتشمل نللك المعلومات معدلات الإصابة بهذه الأمر اض ، خارطة توزيعها في الأقطار المختلفة ومو سم حدوثها ونوعية الحيو انات التي تصاب بها وتتقلها للإنسان، و اسجابتها للعلاج بالأدوية المختلفة وهل هي أمراض مستوطنة أم دافدة، ودرجة فتكها بالحيوان والإنسان وأثرها على إنتاجية الحيو ان وبالتالي قيمتها الاقتصادية وتحديد أولويات مكافحتها ورصد الميز انيات لذلك. 2- ربط مركز المعلومات السابق بشبكات الاتصال العالمية وتزويده بوسائل الإنذار المبكر حتى تربط هذه الوسائل مع شبكة المعلومات الخاصة بالأمر اض وبالتالي تحديد أولويات المكافحة ودرجة الخطورة الناجمة عن المرض بصورة أكثر دقة وشمولاً وذا قيمة. و على ضوء هذه المعلومات تتحدد أولويات مكافحة الأمر اض المشتركة الموجودة في كل منطقة عربية أو كل الدول العربية مجتمعة. 3- دعم قدرات المحاجر البيطرية ومر اكز مكافحة الأوبئة الحيوانية المشتركة والمخابر التتخيصية في الدول العربية حتى تصل كل دولة لمرحلة تشخيص كل الأمراض المنتشرة في المنطقة بشكل سريع ورفع مستوى النتخيص في تلك المخابر لتو اكب مخابر التشخيص العالمية. وتبادل الخبرة والتدريب بين أقطار الوطن العربي. 4- تحديث وسائل الاستقصاء والسيطرة على الأمراض المشتركة بأحدث الوسائل لعلم الوبائيات. 
Study On Zoonoses And Preventive And Control Measures In ...

\begin{tabular}{|c|c|c|c|c|}
\hline الحيو انـات كمصدر للعدوى & أهم طرق الاتقال للإنسان & اسم العامل المسبب & اسم المرض & المجموعة \\
\hline الأبقار، الأغنام، الماعز، الإبل، & 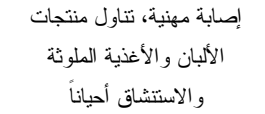 & جر اثيم البروسيلا بأنو اعها الثلاث & داء البروسيلات & \multirow{7}{*}{ 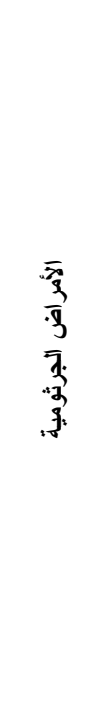 } \\
\hline الأبقار & الاستششاق و الابتلاع و العدوى & العصية السلية النوع البقري & السل البقري & \\
\hline الأبقار، الأغنام و الماعز، الإبل، الكلاب & إصابة مهنية، تتاول اللحوم المصابة، & عصيات الجمرة & الجمرة الخبيثة & \\
\hline 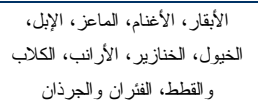 & الغطس في المياه الملوثة، & كافة الأنو اع المصلية لجر اثثي & البريميات & \\
\hline 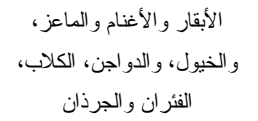 & 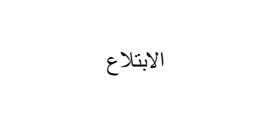 & كافة الأنو اع المصلية لجر اثيم & السلمونيلات & \\
\hline الخيول، الأر انب و الأغنام و الماعز ، & و الاستشاق و التماس اللحوم المصابة & الليستريا وحيدة النواة & الليستريا (الدوران) & \\
\hline الطيور ، الأبقار، الأغنام & 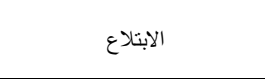 & ذيفانات عصبة المطثية الوشيقية & التسمم بالوشيق & \\
\hline الأبقار ، الأغنام و الماعز & عض الحشر ات و التماس وتداول & فيروس من مجموعة الأربو & حمى الو ادي المتصدع & \multirow{7}{*}{ 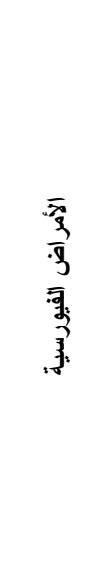 } \\
\hline الأبقار ، الأغنام و الماعز & تتاول حليب الحيو انات الخام & فيروس من مجمو عة رنا الدقيقة & الحمى القلاعية & \\
\hline الكلاب، و الفئر ان و الجزذان & عض الثييات المصابة و إصابة & فيروس الكلب & الكلب & \\
\hline 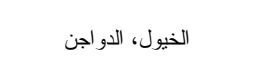 & عض الحشرات التي تحمل & فيروس من مجموعة الأربو & حمى غرب النيل & \\
\hline الأغنام و الماعز & عدوى مهنية & فيروس من مجمو عة أورف & الأكزيما المعدية & \\
\hline 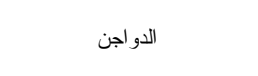 & عدوى مهنية & $\begin{array}{c}\text { فيروس من مجموعة الفيروسات } \\
\text { نظيرة الأنفلونز }\end{array}$ & شبه طاعون الدجاج & \\
\hline الألبقار، الأغنام، الماعز، الخيول، الحمير، الجمال، الخبو، وحيو انات أخرى & القرّّاد، و التماس المباشر & فيروس من مجموعة فيرسات البونيا & حمى القرم الكونغو النزفية & \\
\hline 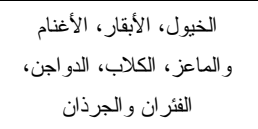 & التماس المباشر وغير المباشر & بعض أنواع الفطور الشعرية & القر اع & $\begin{array}{ll}\overline{3} & \bar{y} \\
\overline{3} & =\frac{7}{7}\end{array}$ \\
\hline الكلاب، الفئر ان و الجرذان & عض الذباب الفاصد (ذباب الرمل) & طفيل الليشمانيا & الليشمانيا & $\overline{x_{3}}$ \\
\hline الأبقار ، الأغنام، الماعز، الدو اجن & الأبتلاع عن طريق الرحم & المقوسات الغندية & داء المقوسات الغندية & $\overline{3}$ \\
\hline الكلاب & الابتلاع & بيوض المشوكة الحبييية & الكيسات المائية & $\overline{9}$ \\
\hline الحيو انات و الطيور المستأنسة و البرية & عن طريق الجروح & الطور اليرقي لذبابة الدودة الحلزونية & الدودة الحلزونية & 承: \\
\hline
\end{tabular}

Kafrelsheikh Vet. Med. J. Vol. 7 No. 1 (2009) 


\section{المراجع REFERENCES}

- المنظمة العربية للتنمية الزراعية (1995): الندوة القومية للأمر اض الوبائية الناتجة عن التجارة الدولية في الثزوة الحيو انية ومنتجاتها.

- المنظمة العربية للتنمية الزراعية (1998): الندوة القومية حول دور الخدمات البيطرية في حماية الثروة الحيو انبة في الوطن العربي.

- المنظمة العربية للتنمية الزراعية (1999): دراسات نطوير الخدمات البيطرية لحماية الثروة الحيو انية وزيادة إنتاجها في الوطن العربي.

- المنظمة العربية للتنمبية الزراعية (1999): الندوة القومية لدراسة المخطط الثامل لتتمية قطاع إنتاج اللحوم الحمر اءو التزويج لمشروعاته في الوطن العربي.

- المنظمة العربية للتنمية الزراعية (1999): التقرير السنوي للتتمية الزر اعية في الوطن

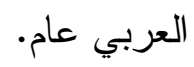

- المنلا ، عبد/الله (2001): علم الأمراض المشتركة بين الإنسان والحيوان. كلية الطب

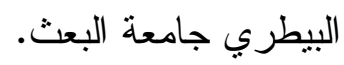

- بلاوي ، رفيق (1991): علم الأوبئة و الأمر اض المعدية، الجزء الأول، كلية الطب

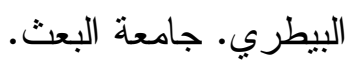

- بلاوي، رفيق (1990): عم الأوبئة والأمر اض المعدية، الجزء الثاني، كلية الطب البيطري جامعة البعث. 
- بلاوي، رفيق (1993): الأمر اض المشتركة بين الإنسان و الحيوان، أهميتها، تصنيفها،

انتقالها وسبل الوقاية منها ومكافحتها. جامعة تشرين للاراسات و البحوث العلمية المجلد

- بلاوي رفيق، وعبد العزيز فهيم(2000): صحة الحيو ان.كلية الزر اعة جامعة تشرين. - جبلاوي رفيق، عبل العزيز فهيم (2001): أمر اض الحيوان.كلية الزر اعة جامعة تشرين.

- Arsov, R. (1992): Obshti svidenia za zoonozite, kniga za zoonozitebolesti obshti za jyvotnite i tshuveka, zemizdat Sofia.

- Hubbert, W., Mcculloen, W. F.; Schnurrenberger, P.R. (1975): Diseases transmitted from animals to man. $6^{\text {th }}$ Ed. Charles, Thomas. Publisher, springlied Ilionosis. USA.

- Jeblawi, Gonwa., Nesafe, Ali., Tbaa, Darem (2008): Study on The Prevalence of Hydatid Cysts in Syrian Coast and Its Influence on Animal Production.

- Office international of epizooticae, Paris 2001.

- Schwabe, C.W. (1969): Veterinary medicine and human heath, $2^{\text {nd }}$ Ed. Williams, Wilkins Co., Baltimore.

- Who, (1967): Technical report series, No. 378 (Zoonoses, therd report of the Joint FAO (WHO expert committee).

- Who, (1990): Technical report series, No. 740 (Brucellosis: six report of the Joint FAO / WHO expert committee). 